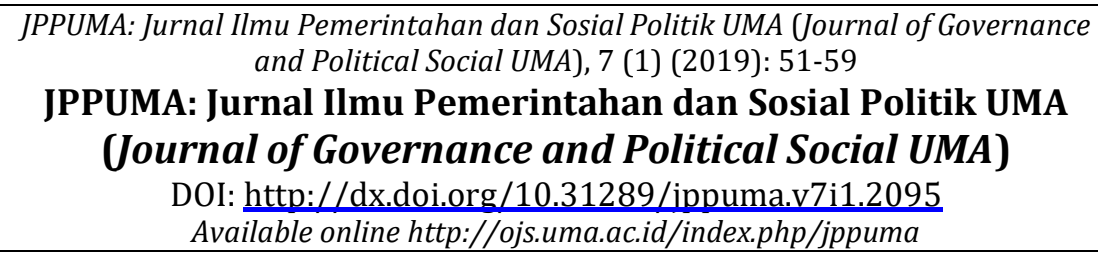

JPPUMA: Jurnal Ilmu Pemerintahan dan Sosial Politik UMA

(Journal of Governance and Political Social UMA)

DOI: http://dx.doi.org/10.31289/ippuma.v7i1.2095

Available online http://ojs.uma.ac.id/index.php/jppuma

\title{
Tinjauan Reflektif Media Massa dalam Pendidikan Politik di Indonesia
}

\section{Reflective Review of Mass Media in Political Education in Indonesia}

\author{
Toba Sastrawan Manik*) \& Suharno
}

Jurusan Pendidikan Pancasila dan Kewarganegaraan, Program Pascasarjana, Universitas Negeri Yogyakarta, Indonesia

Diterima: Desember 2018; Disetujui: Februari 2019; Dipublish: Juni 2019

\begin{abstract}
Abstrak
Tujuan artikelini adalah untuk mengkaji bagaimana eksistensi dan fungsi pendidikan politik media massa di Indonesia khususnya sejak Era Reformasi. Metode yang dilakukan dalam artikel ini adalah pendekatan induktif dengan teknik pengumpulan data studi kepustakaan (library research).Kajian ini menemukan bahwa media massa memainkan peran penting dalam pendidikan politik di Indonesia. Media massa dalam negarademokrasi tidak hanya berperan sebagaipenyedia informasi, namun juga sebagai mediumpolitical change terjadi dimasyarakat. Media massa terikat dengan sistem politik itu sendiri. Kajian ini juga menemukan akar permasalahan pendidikan politik diIndonesia adalah adanya inequality (ketidaksamarataan) struktur penguasaan media di Indonesia sehingga media cenderung mengalami deviasi dan keberpihakan politik dalam pemberitaan. Di sini dibutuhkan refleksi pendidikan politik di media massa. Namun arus Reformasi sejak tahun 1998 tidak begitu menggembirakan dalam perkembangan pendidikan politik di media massa. Hadirnya media online dan jaringan internet luas diharapkan dapat menjadi alternatif pendidikan politik, namun terbentur dengan rendahnya angka literasi masyarakat. Keberpihakan media ini tidak bisa dihilangkan, melainkan hanya bisa diminimalisir dengan memperkuat pendidikan politik di sektor lain seperti keluarga, sekolah dan masyarakat. Sekalipun demikian media massa tetap memiliki peran signifikan dalam pendidikan politik namun membutuhkan prasyarat tingkat literasi yang tinggi.
\end{abstract}

Kata Kunci: Media Massa, Pendidikan Politik, Ketidaksamarataan, Literasi.

\begin{abstract}
This article aims to study how the existance and function of political education in Indonesian mass media since Reformation Era.The method used in this article is an inductive approach with library research data collection techniques. This study found that mass media played an important role in political education in Indonesia. The mass media in democracy stateare not only as an information provider, but also as medium of political change of society. The mass media tied to the political system itself. But this study also found the root of the problem of political education in Indonesia was the existence of inequality in the structure of media control in Indonesia so that the media tended to experience deviations and political alignments in reporting. Here we need a reflective moment of political education in the mass media. However, Reformation wave in 1998 was not very encouraging in the development of political education in the mass media. The presence of online media and extensive internet networks was expected to be an alternative to political education but collided with the low level of public literacy. This media alignment cannot be eliminated but can only be minimized by strengthening political education in other sectors such as family, school and society. Even so, mass media still has a significant role in political education but requires a high level of literacy prerequisites.
\end{abstract}

Keywords: Mass Media, Political Education, Inequality, Literacy.

How to Cite: Manik' T.S. \& Suharno (2019). Tinjauan Reflektif Media Massa dalam Pendidikan Politik di Indonesia, JPPUMA: Jurnal Ilmu Pemerintahan dan Sosial Politik UMA Uournal of Governance and Political Social $U M A), 7$ (1): 51-59.

*Corresponding author: ISSN 2549-1660 (Print) toba0204pasca.2018@student.unv.ac.id ISSN 2550-1305 (Online) 


\section{PENDAHULUAN}

Louisa Valenzuela, sastrawan Argentina pernah mengatakan bahwa manusia tidak bisa lepas dari kehidupan politik. Menurutnya, laiknya seperti jaring laba-laba segenap kehidupan berkaitan dengan politik. Dunia bernafas, makan dan berak politik. Namun politik bukanlah sesuatu yang vakum, hampa dan statis. Muatan politik sangat kompleks dan luas maka mempelajari politik tidak mudah. Dalam terminologi politik, setidaknya ia memiliki tiga dimensi yakni dimensi politik sebagai studi kelembagaan, dimensi politik sebagai studi kekuasaan dan politik sebagai studi kebijakan publik (Cangara,2009). Lebih luas menurut Carr (2011) teori politik mempertimbangkan "(a) the legitimacy of the state; and (b) the articulation of principles, values, ideals, and concepts that are intended to inform and direct the legitimate activities of the state, it must necessarily be considered a dimension of moral philosophy."

Manusia sebagai zoon politicon atau subjek politik harus dipahami oleh masyarakat. Masyarakat suatu negara harus memahami struktur-struktur lembaga negara yang mengatur mereka, harus kritis terhadap proses peralihan dan pelaksanaan kekuasaan yang didelegasikan kepada perwakilan.Maka pendidikan politik terhadap masyarakat adalah sesuatu yang harus ada dalam suatu negara khususnya negara demokrasi. Pendidikan politik dalam hal ini bisa didefinisikan sebagai usaha/upaya untuk memahamkan dan membangun pengetahuan dan perilaku masyarakat dalam politik.

Political Education secara ringkas didefinisikan oleh Birzea adalah sebagai proses dimana masyarakat dapat/mampu baik secara individu dan atau kelompok menganalisa dan mempengaruhi proses pembuatan keputusan politik (2000). Melalui pendidikan politik karakter masyarakat dibentuk sehingga mampu aktif dan menjadi warga negara yang partisipatif. Secara ringkas, pendidikan politik dapat dilaksanakan lewat dua jalur: jalur pendidikan formal dan jalur pendidikan non formal (Sunarno, 2007).

Dalam hal pendidikan politik, media massa juga bisa memainkan peran signifikan. Menurut Beetham \& Boyle (2006) dalam demokrasi media massa dapat berfungsi menyelidiki pemerintah, memberikan informasi bagi publik,menyediakan forum bagi debat politik, dan bertindak sebagai saluran bagi opini publik dan tekanan atas pemerintah. Jika melihat fungsi-fungsi di atas, secara teoritis benarlah bahwa media massa sangat berperan signifikan dalam pendidikan politik di masyarakat.

Saat ini menurut Dewan Pers Indonesia memiliki jumlah media massa mencapai 47.000 yang terdiri dari media cetak, online, radio, televisi. Dengan ini menempatkan Indonesia posisi negara terbanyak media massa. Penguasaan sumber-sumber informasi merupakan bentuk kekuasaan baru dalam demokrasi. Media massa berperan penting dalam pendidikan politik misalnya dalam perilaku memilih. Seiring dengan kemajuan teknologi media massa baik online maupun cetak menjadi sumber preferensi politik masyarakat lewat pemberitaan politik dan iklan-iklan politik sehingga menjadi sumber informasi dan ruang keterlibatan politik masyarakat. Hal ini bisa dilihat dari tingkat penggunaan masyarakat menggunakan internet. Menurut data Hotsuite 2018 sebagaimana dipaparkan oleh Sutanto (2018) bahwa dari 265 juta rakyat Indonesia, 132,7 Juta aktif menggunakan internet, 130 juta sebagai pengguna media sosial. Dalam keadaan ini, pendidikan politik lewat media massa khususnya dalam bentuk online sangat mudah dan masif diterima masyarakat. Hal ini menegaskan peran vital media massa dalam pendidikan politik masyarakat.

Lantas bagaimana peran pendidikan politik oleh media massa ditinjau dari 
kajian teoritis di negara demokrasi khususnya Indonesia?Bagaimana eksistensi kepemilikan media massa di Indonesia dan pengaruhnya terhadap relevansi pendidikan politik Era Reformasi? Permasalahan ini diharapkan dapat menghantarkan kita kepada pemahaman urgensi, posisi dan relevansi media massa dalam pendidikan politik. Namun juga kesadaran kritis atas kinerja dan progres pendidikan politik media massa di Indonesia.

\section{METODE PENELITIAN}

Jenis penelitian dalam artikel ini adalah deskriptif. Penelitian yang bertujuan untuk membuat deskripsi atau gambaran secara sistematis, faktual dan actual fenomena yang diselidiki (Nazir, 2013). Metode yang digunakan adalah studi kepustakaan (library research) yakni mengkaji dari sumber-sumber pustaka tentang politik, pendidikan politik, media massa dan tentang penelitian yakni 14 buku, 5 jurnal, 1 dokumen laporan penelitian, 1 makalah seminar nasional dan 3 situs internet. Pendekatan yang digunakan dalam kajian ini adalah pendekatan induktif yakni menyimpulkan dari khusus ke umum.

\section{HASIL DAN PEMBAHASAN}

\section{Pengertian Pendidikan Politik}

Definisi pendidikan politik sangat beragam. Tidak hanya itu, pengertian antara pendidikan politik dan sosialisasi politik (political sosialization) juga kerap menimbulkan multitafsir. Namun perbedaan itu tidaklah mengaburkan makna atas pentingnya pendidikan politik tersebut.

Ada banyak pendapat ahli tentang pedidikan politik yang mencoba meletakkan konsep dasar pendidikan politik. Menurut Kantaprawira (2004) pendidikan politik sebagai cara untuk meningkatkan pengetahuan rakyat agar mereka dapat berpartisipasi secara maksimal dalam sistem politiknya. Tidak hanya menekankan pada aspek kognitif, menurut Kartono (1996) dengan adanya pendidikan politik maka bukan hanya pemahaman peristiwa-peristiwa politik dan konflik yang diutamakan, akan tetapi orang justru menekankan aktivitas politik secara sadar dan benar dengan azas-azas demokrasi sejati.

Pendidikan politik juga terikat dengan lingkungan sekitar individu berada. Maka K. Atkin \& Gantz (1978) mendefinisikan bahwa: "Political socialization is a developmental process by which children and adolescents acquire cognitions, attitudes, and behaviors relating to their political environment. Secara ringkas dan lebih tegas, Birzea (2000) mendefinisikan pendidikan politik sebagai proses dimana masyarakat dapat/mampu baik secara individu dan atau kelompok menganalisa dan mempengaruhi proses pembuatan keputusan politik.

Dalam Undang-undang No. 2 Tahun 2011 Tentang Partai Politik mendefinisikan bahwa "Pendidikan Politik adalah proses pembelajaran dan pemahaman tentang hak, kewajiban, dan tanggung jawab setiap warga negara dalam kehidupan berbangsa dan bernegara (Pasal 1 ayat [a4])."

Dari beberapa pendapat diatas sekalipun beragam namun dapat ditarik garis lurus persamaan pandangan bahwa tujuan dari pendidikan politik tetap pada peningkatan kualitas masyarakat bahwa secara afektif, kognitif dan psikomotor dalam kehidupan masyarakat. Sebagaimana ditegaskan oleh Dekker and Arie in 't Veld (2014): "Political socialization is the whole of those processes and structures through which people develop particular political behaviors and acquire particular political orientations, including political behavioral intentions, emotions, values, attitudes, opinions, beliefs or perceptions, and knowledge." 
Di sinilah esensi penting pendidikan politik. Pendidikan politik berfungsi sebagai sesuatu hal yang esensial dan terus-menerus dilakukan dalam masyarakat. Pendidikan politik sama pentingya dengan eksistesi politik itu sendiri. Politik tanpa pendidikan politik adalah kebutaan sedangkan pendidikan politik tanpa politik adalah kehampaan. Sederhananya, efektivitas berjalannya sistem politik ditentukan oleh pendidikan politik (Handoyo\& Lestari,2017).

\section{Bentuk Pendidikan Politik}

Pendidikan politik beragam dalam implementasinya. Pendidikan politik tergantung kepada siapa yang menjadi pelaksananya atau subjeknya. Bentuk pendidikan politik menurut Kantaprawira (2004) dapat diselenggarakan antara lain: Bahan bacaan seperti suratkabar, majalah, dan lain-lain bentuk publikasi masa yang biasa membentuk pendapat umum; (b) Siaran radio dan televisi serta film (audio visual media); (c) Lembaga atau asosiasi dalam masyarakat seperti masjid atau gereja tempat menyampaikan khotbah, dan juga lembaga pendidikan formal (sekolah) ataupun informal.

Pendidikan politik tentunya tidak akan terlaksana tanpa adanya penyelenggaraan yang dilakukan secara konkret di lapangan atau di tengah-tengah masyarakat. Kuntowijoyo mengemukakan tentang bentuk pendidikan politik, yakni: Pendidikan politik formal yakni pendidikan politik yang diselenggarakan melalui indoktrinasi; (b) Pendidikan politik yang dilakukan secara non-formal, seperti melalui pertukaran pendidikan melalui mimbar bebas. Pendidikan politik yang baik adalah pendidikan politik yang memobilisasi simbol-simbol nasional, seperti sejarah, seni sastra, dan bahasa (1994).

Pendidikan politik jalur formal adalah pendidikan lewat struktur resmi yakni jenjang kependidikan jalur sekolah. Sedangkan pendidikan politik non-formal bisa dikatakan adalah pendidikan diluar sistem pendidikan (sekolah) dengan kata lain yang dilaksanakan oleh masyarakat umum. Dengan kata lain cara pendidikan yang diterima baik di lingkungan keluarga dan masyarakat luas (Purwanto dalam Pasaribu, 2017).

Sedangkan menurut J. Benter (1967) bentuk pendidikan politik terbagi atas dua yakni laten dan manifest (nyata). Menurutnya "Political socialization is manifest when political feelings, values, beliefs, transmitted explicitly. This connotes the idea of the intentional teaching values, beliefs, etc. The process is latent when the cognitions, beliefs, implicitly derived from other social systems - i.e., family."

\section{Tujuan Pendidikan Politik}

Sebagaimana disinggung sebelumnya bahwa pendidikan politik adalah upaya untuk membentuk sikap dan karakter warganegara yang konstruktif terhadap sistem politik. J. Bender (1967) mengatakan muara dari pendidikan politik adalah perubahan politik (political change). Menurut Gerald "There are at least two levels of political change: systemic and non-(or intra-) sytemic change. The former refers to a change in the distribution and exercise of authority. The two ideal extremes would of course be pure democracy and pure totalitarianism with gradations between."

Secara lebih luas Kartono (1989) dalam Handoyo dan Lestari (2017) merinci tujuan dari pendidikan politik yakni: (a) Membuat rakyat (individu, klien, anak didik, dan warga/masyarakat) mampu memahami situasi sosial politik yang penuh konflik, berani memberikan kritik membangun terhadap kondisi masyarakat yang tidak mantap; aktivitasnya diarahkan pada proses demokrasi sejati; (b) sanggup memperjuangkan kepentingan serta ideologi tertentu, khususnya yang berkorelasi dengan keamanan dan kesejahteraan hidup bersama dan 
Memperhatikan peranan insani dari setiap individu sebagai warganegara, mengembangkan semua bakat dan kemampuannya (pengetahuan, wawasan, sikap, keterampilan dan lain-lain), agar ia dapat aktif berpartisipasi dalam proses politik demi pembangunan bangsa dan negara.

Dari hal ini bisa dipahami bahwa pendidikan politik berupaya untuk menciptakan warga negara yang ideal bagi negara atau sistem politik. Negara baik mensyaratkan warga negara yang baik. Disinilah pendidikan politik berupaya menjembatani dan menciptakan warga negara yang baik tersebut.

\section{Pendidikan Politik oleh Media Massa}

Dalam perspektif demokrasi, media massa menempati posisi sangat penting. Media massa lazimnya disebut sebagai pilar demokrasi keempat. Hal ini disebabkan karena urgensi dan relevansi media massa diharapkan mengimbangi kekuasaan-kekuasaan lembaga politik seperti legislatif, eksekutif dan yudikatif.

Maka media massa tidak hanya menjadi sumber lalu lintas informasi. Namun sebagai bagian pilar demokrasi juga terlibat urusan kekuasaan. Hal senada dinyatakan Cangara (2011) "Pers tidak saja berfungsi pemberi informasi, tetapi juga sebagai alat kontrol terhadap ketidakpatutan para penguasa atas hakhak sipil."

Media massa atau pers yang dimaksud dalam hal ini ialah baik yang bersifat online (daring) maupun bukan, elektronik maupun cetak. Sebab, klasifikasi-klasifikasi tersebut hanya pada tataran bentuk dan mode penyampaian pendidikan politik kepada masyarakat. Media online akan berkaitan dengan pengunjungnya (viewer), elektronik seperti televisi akan berkaitan dengan rating-nya sedangkan koran atau majalah akan berkaitan dengan oplahnya.
Media massa yang ada dan menjadi bagian tidak terpisahkan dari demokrasi tidak hanya dilihat dari eksistensinya namun juga dari fungsi-fungsi yang harus dijalankan. Jika kita mengacu pada UU No. 40 Tahun 1999 Tentang Pers dalam Pasal 3 ayat (1) maka disebutkan "pers nasional mempunyai fungsi sebagai media informasi, pendidikan, hiburan, dan kontrol sosial."

Pendidikan yang dimaksud dalam hal ini bersifat luas termasuk didalamnya adalah pendidikan politik. Pendidikan politik yang dilaksanakan media massa berdasarkan penjelasan sebelumya ialah pendidikan non formal yakni pendidikan yang diadakan diadakan di masyarakat secara bebas dan non formal. Pendidikan termasuk juga pendidikan politik yang bersifat laten menurut bahasa J, Bender (1967) yakni pendidikan yang dikembangkan dilingkungan sosial.

Pendidikan politik memiliki peran semakin strategis seiring dengan perkembangan teknologi. Peralihan media cetak menuju media online tidak sertamerta mematikan peran vital pendidikan politik dalam media massa. Justru sebaliknya, media massa memainkan peran semakin signifikan seiring dengan meningkatnya media-media massa online yang tumbuh.

Menurut Dewan Pers Indonesia memiliki jumlah media massa mencapai 47.000 yang terdiri dari media cetak, online, radio, televisi. Dengan ini menempatkan Indonesia posisi negara terbanyak media massa. Jumlah ini sangat besar dan potensial jika dimanfaatkan dan dikelola dengan baik dalam pendidikan politik. Media sosial sebagai sebuah subsistem di masyarakat tentu memiliki pengaruh dalam pembentukan sikap, perilaku atau budaya politik masyarakat. Mengutip dari Duverger (2015) "Lembaga-lembaga sosial memiliki pengaruh yang tidak dapat disangkal terhadap fenomena politik. Bahkan sistem 
perkawinan, sistem sekolah dan etiket sosial mempengaruhi politik."

Menurut data Hotsuite Indonesia 2018 sebagaimana dipaparkan oleh Sutanto (2018), jumlah pengguna internet di Indonesia mencapai 132 juta penduduk dimana 130 juta diantaranya aktif menggunakan media sosial dan 79\% menggunakan internet tersebut setiap hari. Hal ini tentu menempatkan media massa khususnya media massa online menjadi sangat strategis sebagai pusat diseminasi pendidikan politik di Indonesia.

Pertanyaan pentingnya adalah bagaimana media menjalankan pendidikan politik tersebut? Atau dengan kata lain bagaimana media massa bisa menegakkan atau mengisi politik atau sistem demokrasi itu sendiri atau apa yang hendak diharapkan dari media sehingga sedemikian pentingnya dalam sistem politik demokrasi?

Menurut Blumber dalam Coleman, dkk (2015) beberapa hal yang diharapkan demokrasi terhadap media yakni: pengamatan terhadap perkembangan sosial politik; mengidentifikasi isu-isu yang sangat relevan; menyediakan bentuk perdebatan dari berbagai sudut pandang; menagih pertanggungjawaban penguasa; (b) memberikan dorongan bagi warga negara untuk belajar, memilih, dan terlibat dalam proses politik; (c) mempertahankan independensi dan kemerdekaan mereka."

Menurut Beetham \& Boyle (2000), dalam demokrasi media massa dapat berfungsi menyelidiki pemerintah, memberikan informasi bagi publik,menyediakan forum bagi debat politik, dan bertindak sebagai saluran bagi opini publik dan tekanan atas pemerintah.

Dari pendapat diatas dapat dilihat peran penting media massa dalam pendidikan politik. Media massa tidak lagi hanya saluran dan sumber lalu lintas informasi melainkan berperan penting dalam membentuk sikap politik sebagaimana esensi dari pendidikan politik itu sendiri.

Lebih tegas diungkapkan oleh Schroeder (2018) bahwa: Media are a 'subsystem', the transmission belt within the political system (even if media subsystems also separately serve the cultural system, as with socializing and information seeking, or the economic system, as with consuming entertainment, for example): their autonomy is from the public, from elites and from the political apparatus - but media serve to promote (or not) political change.

Media massa dan politik khususnya demokrasi memiliki keterikatan satu sama lain. Media massa bergantung [kepada] iklim dan suasana politik demokrasi agar memiliki kebebasan dan kekuasaan berbeda dengan pada sistem politik otoritarianisme. Namun pada sisi lain media massa memiliki kewajiban atau fungsi untuk mempromosikan politik baik secara perubahan atau konservasi. Hal inilah yang sesungguhnya menjadi esensi tujuan pendidikan politik sebagai dimaksud diawal oleh Gerald yakni political change.

\section{Refleksi Pendidikan Politik Media Massa pada Era Reformasi}

Era Reformasi memiliki peran penting dalam pelaksanaan esensi demokrasi di Indonesia. Kebebasan pers merupakan salah satu dari banyak agenda yang diusung gerakan reformasi. Menurut Aziz dan Hidayat (2016) setidaknya ada 12 (dua belas) ciri-ciri sistem politik Indonesia pada Era Reformasi: a) Demokrasi Pancasila, sistem pemerintahan presidensial; Diadakan kembali pemilu tahun 1999; (b) Dibuka kemerdekaan dan kebebasan pers sebagai media komunikasi politik yang efektif; (c) Upaya peningkatan partisipasi rakyat dalam kegiataan pemerintahan; (d) Amandemen UUD 1945 untuk mengatur kekuasaan dalam negara agar lebih demokratis; (e) Pelaksanaan otonomi 
daerah; (f) Reposisi dan reaktualisasi TNI; (g)Pemilu Luber dan Jurdil (Pilkada untuk daerah); (h) Upaya penegakan HAM; (i) Upaya netralisasi berpolitik bagi PNS; (j) Upaya pemberantasan KKN; Penegakan supremasi hukum dan keadilan ekonomi.

Dari tema-tema yang coba dibangun pada Era Reformasi tampak bahwa kesadaran akan pentingnya eksistensi media massa atau pers sebagai komunikasi politik yang efektif. Komunikasi dalam hal ini tentu tidak pertukaran informasi semata melainkan seperti definisikan oleh Schroeder (2018) bahwa 'communication' as comprising two- way one- to- one or one- to- many messages, whereas 'information' means the one- way obtaining of knowledge or data that makes a difference - in this case to how citizens cope with the political environment (or more broadly, makes a difference to how they cope with the physical and social environment."

Dalam tataran struktural organisasi media massa itu sendiri tampak adanya dominasi atas media itu oleh kelompok kepentingan tertentu. Dominasi yang dimaksud dalam hal ini struktur komunikasi massa, seperti jaringan surat kabar, televisi jaringan nasional, dan penerbit dengan pasar luas sebagai alat untuk menyuarakan kebebasan pers telah dimonopoli oleh kelompok kepentingan. Kelompok kepentingan dalam hal ini adalah korporasi besar baik domestik maupun internasional (Mutfi \& Naafisah, 2013). Bisa dipahami bahwa media massa kekinian telah terjebak dalam perangkap kapitalisme atau kepentingan ekonomi. Atas dasar kepentingan ekonomi tersebut akhirnya media-media arus utama dikuasai kelompok kepentingan baik kepentingan ekonomi maupun politik.

Di Indonesia hal ini begitu kentara ketika kita mengamati media arus utama televisi. Televisi Metro TV, TV One, MNC Group bisa dengan mudah ditebak akan berpihak kepadasalah satu tokoh/kubu politik. Hal ini disebabkan para pemegang saham koorporasi tersebut terjun kedalam dunia politik praktis seperti Surya Paloh, Harry Tanoe yang secara terang-terangan mendeklarasikan dukungan politiknya.

Tidak hanya dalam bentuk televisi, korporasi media tersebut lazimnya memiliki media cetak dan media online yang sifat dan tendensinya "setali tiga uang" dengan televisi. Sehingga konten, berita dan materi yang diseminasikan oleh media arus utama tersebut memiliki keberpihakan terhadap salah satu kelompok kepentingan yang besar.

Menurut Philip Green dalam Mutfi \& Naafisah (2013) struktur media tersebut tidak sesuai dengan struktur kewarganegaraan demokratis dimana prinsip keterwakilan, hubungan saling menguntungkan dan non-alienasi, serta rotasi peran dan tanggungjawab yang berkelanjutan antara yang diwakili dan mewakili ditempatkan pada prinsip mendasar.

Akhirnya yang terjadi adalah ketimpangan arus informasi. Media massa dengan aliansi kepentingan politik tersebut akan berupaya membangun citra sebaik mungkin atas figur, tokoh politik yang menjadi pemimpi dalam kelompok kepentingan tersebut. Akhirnya penguasaan media oleh kelas dominan tersebut menimbulkan masalah inequality bagi setiap warga negara yang membutuhkan akses terhadap informasi dan artikulasi kepentingan publik (Mutfi \& Naafisah, 2013).

Lebih lanjut menurut Green dikutip dari buku yang sama mengatakan bahwa masalah inequality penguasa media massa tidak bisa dihilangkan namun hanya bisa diminimalisir. Menurutnya tindakan meminimalisir tersebut ialah menjamin ketersediaan teknologi cetak dan media gambar dan bisa dijangkau oleh individu maupun kelompok di masyarakat lewat fasilitas teknis yang dibagikan, pemeliharaan saluran komunikasi dan distribusi jaringan sehingga tidak 
didominasi oleh penguasa atau korporasi besar (Philip Green dalam Mutfi \& Naafisah, 2013).

Strategi dari Green ini disatu sisi bisa diterima akal di mana ia menginginkan perimbangan dominasi media massa tersebut dengan pengembangan media informasi berbasis internet yang secara meluas diterima masyarakat. Disatu sisi hal ini bisa diterima mengingat tingkat penggunaan internet di Indonesia sangat tinggi yakni jumlah pengguna internet di Indonesia mencapai 132 juta penduduk dimana 130 juta diantaranya aktif menggunakan media sosial dan $79 \%$ menggunakan internet tersebut setiap hari dan didukung oleh 47.000 media massa baik online maupun cetak yang ada di Indonesia.

Namun disisi lain, tingkat literasi Indonesia yang rendah menjadi masalah. Dalam keadaan tingkat literasi yang rendah ditengah hegemoni dan masifnya media-media informasi menjadikan berita palsu atau bohong mudah diterima. Hal senada dinyatakan Mutfi \& Naafisah (2013) "Untuk kasus di Indonesia, tingkat buta hurufnya yang masih tinggi dan penguasaan teknologi yang masih rendah, tentu saja hal ini menjadi masalah dalam memperoleh akses informasi."

Masalah lainnya adalah muncul situs-situs media online yang kurang kredibel dan bertanggungjawab. Menurut Ketua Dewan Pers (Yunizafira, 2018), Yosep Stanley Adi Prasetyo mengatakan total media di Indonesia saat ini ada sekitar 47 ribu dengan paling banyak oleh media online. Namun, hanya ada 168 media yang telah terdata di Dewan Pers. Sedangkan menurut data Kominfo (Ayu, 2017) di Indonesia setidakya terdapat 800.000 situs penyebar hoax di Indonesia. Hasil penelitian Badan Intelijen Negara (Ambaranie, 2018) tidak jauh berbeda bahwa $60 \%$ konten media sosial adalah informasi hoax.

Hal ini menjadi tantangan bagi demokrasi Indonesia. Sebagaimana diuraikan sebelumnya dimana media massa memainkan peran penting dalam membentuk karakter dan sikap politik warga negara. Jika peran media massa akan tetap seperti ini tentu bersifat destruktif terhadap demokrasi Indonesia. Tentu dengan catatan tegas dibuat dalam hal ini bahwa tidak semua media massa di Indonesia yang berafiliasi dengan kepentingan politik tertentu. Namun mengingat kuantitas yang berafiliasi lebih dominan tentu akan tetap mengkhawatirkan.

Sebagai solusi dalam problematika ini adalah tetap mengkritik dan mengembangkan kepercayaan terhadap media-media arus utama yang independen, pendidikan politik jalur lainseperti jalur keluarga, sekolah dan masyarakat harus berperan aktif. Masyarakat harus cerdas dan kritis memilah informasi yang ada. Tentu syaratnya dalam hal ini adalah mengedepankan aspek pertimbangan rasional ketimbang emosional dalam membaca, mendengar dan menyimak berita. Intinya masyarakat harus memiliki kecerdasan literasi. Kecerdasan literasi dalam hal ini seperti dikatakan Taufik (2018) tidak hanya sebatas kemampuan membaca (read) namun juga kemampuan menulis atau menghasilkan (create) pandangan, opini yang kritis di sinilah kreativitas (creativity) dibutuhkan.

\section{SIMPULAN}

Media massa memiliki peran penting dalam pendidikan politik. Media massa tidak hanya media komunikasi semata melainkan menjadi alat transfer nilai, keyakinan dan sikap dalam politik. Media massa termasuk dalam pendidikan jalur non-formal yakni pendidikan yang berada ditengah-tengah masyarakat atau diselenggarakan diluar jalur formal yakni sekolah atau universitas.

$$
\text { Sejak Era Reformasi terjadi }
$$
inequality dalam penguasaan struktur 
media massa dimana media massa arus utama kebanyakan dimiliki oleh para penguasa yang juga terlibat dalam politik praktis. Sehingga pemberitaan dalam media massa cenderung berpihak dan tidak adil. Solusi dari Green yang mengatakan bahwa hal ini bisa diminimalisir dengan jaminan fasilitas dan distribusi jaringan internet dan informasi dalam konteks Indonesia tidak sepenuhnya bisa diterima karena tingkat literasi atau buta huruf yang masih tinggi. Hal ini kemudian memudahkan tersebarnya berita-berita hoax..

\section{DAFTAR PUSTAKA}

Aziz, M. \& Hidayat, S. (2016). Dinamika Sistem Politik Indonesia. Bandung: Setia Pustaka.

Beetham, D \& Boyle, K. (2006). Demokrasi 80 Tanya Jawab.Yogyakarta: Kanisius.

Cangara, H. (2011). Komunikasi Politik, Konsep,Teori dan Strategi. Jakarta: RajaGrafindo Persada.

Coleman, S. Moss, G, \& Parry, K. (2015). Can The Media Serve Democracy? England: Palgrave Macmillan.

Dekker, H. \& Veld, A. (2014). E-Political Socialization. Bern: Peter Lang Publishing Group

Duverger, M. (2010). Sosiologi Politik. Jakarta: PT RajaGrafindo Persada.

Handoyo, E. \& Lestari. (2017). PendidikanPolitik. Yogyakarta: Pohon Cahaya.

Kartono, K. (1996). Pendidikan Politik. Bandung: Mandar Maju.

Kuntowijoyo. (1994). Demokrasi dan Budaya Birokrasi. Yogyakarta: Benteng Budaya.

Mutfi \& Naafisah, D. (2013). Teori-Teori Demokrasi. Bandung: Setia Pustaka.

Nazir. (2003). Metode Penelitian. Bogor: Ghalia Indonesia.

Kantaprawira, R. (2004). Sistem Politik Indonesia (Suatu Model Pengantar), EdisiRevisi. Bandung: Sinarbarual Gensindo.
Schroeder, R. (2018). Social Theory after the Internet Media, Technology, and Globalization. London: UCL Press.

Carr, P.R. (2011). Critical Pedagogy and Democracy (Counterpoints: Studies in the Postmodern Theory of Education. Bern: Peter Lang Publishing Group

J. Bender, G. (1967). Political Socialization and Political Change. The Western Political Quarterly, 20 (2) : 390-407

K. Atkin, C. \& Gantz, W. (1978). Television News and Political Socialization. The Public Opinion Quarterly, 42(2): 183-198

Pasaribu, P. (2017). Peranan Partai Politik dalam Melaksanakan Pendidikan Politik,JPPUMA: Jurnal Ilmu Pemerintahan dan Sosial Politik, 5(1):51-59

Sunarno. (2007). Politik Pendidikan dan Pendidikan Politik,Jurnal Civic, 4(2): 20-29

Birzea. 2000. Education for Democratic Citizenship: A Lifelong Learning Perspective. Starsbourg: EDC.

Sutanto, T. (2018). Peran Literasi dan Budaya Digital dalam Pendidikan Era Modern dan Industri Era 4.0. Makalah Seminar Nasional Implementasi Riset dan Literasi Untuk Meningkatkan Keterampilan Abad-21, 03 November di Universitas Negeri Yogyakarta.

Putri, Y. (2018). 43.300 Media tak terdaftar di Dewan Pers. Diunduh dihttps://www.merdeka.com/peristiwa/43 300-media-tak-terdaftar-di-dewanpers.html, diakses 05/November/2018

Yuliani, A, (2017). Ada 800.000 Situs Penyebar Hoax di Indonesia. Diunduh https://kominfo.go.id/content/detail/1200 8/ada-800000-situs-penyebar-hoax-diindonesia/0/sorotan_mediadiakses 05/November/2018

Movanita, A.N.K. (2018). BIN: 60 Persen Konten Media Sosial adalah Informasi Hoaks. Diunduh di https://nasional.kompas.com/read/2018/0 3/15/06475551/bin-60-persen-kontenmedia-sosial- adalah-informasi-hoaks, diakses 05/November/2018

UU No. 40 Tahun 1999 Tentang Pers. 